\title{
Voltage regulation of uninterrupted power supplies
}

\begin{abstract}
Uninterrupted Power Supply (UPS) systems are used as one solution of power quality problems and to provide ultimate protection for power disturbances such as power blackouts and brownouts. Many UPS systems suffer from poor output voltage regulation especially with heavy loads. This work is aimed to design and implement the UPS hardware system capable of producing continuous and constant $230 \mathrm{Vac}, 50 \mathrm{~Hz}$ output supply. A feedback loop has been implemented using microcontroller to adjust the dc level supplying the UPS inverter. At the end of the hardware implementation, tests have been carried out to determine the reliability and effectiveness of the designed system, and a good results have been obtained in improving the voltage regulation.
\end{abstract}

Keyword: Uninterruptible Power Supply (UPS); Voltage regulation; Power quality problem 